\title{
Camptothecin regulates microglia polarization and exerts neuroprotective effects via the AKT/Nrf2/HO- $1-N F-K B$ signal axis in vivo and in vitro
}

dewei he

Jilin University https://orcid.org/0000-0003-3062-0633

Dianfeng Liu

Jilin University

Ang Zhou

Jilin University

Xiyu Gao

Jilin University

Yufei Zhang

Jilin University

Yingchun Su

Jilin University

Bingxu Huang

Jilin University

Jian Du

Jilin University

Shoupeng Fu ( $\square$ fushoupeng@jlu.edu.cn )

Jilin University

\section{Research}

Keywords: Camptothecin, Parkinson's disease, M1/M2 microglia, Neuroinflammation

Posted Date: July 23rd, 2020

DOl: https://doi.org/10.21203/rs.3.rs-46120/v1

License: (c) (1) This work is licensed under a Creative Commons Attribution 4.0 International License.

Read Full License 


\section{Abstract \\ Background}

Parkinson's disease (PD), the second largest neurodegenerative disease seriously affects human health. Microglia, the main immune cells in the brain participate in the innate immune response in the central nervous system (CNS). Studies have shown that microglia can be polarized into pro-inflammatory M1 and anti-inflammatory M2 phenotypes. Accumulated evidences suggest that over-activated M1 microglia release pro-inflammatory mediators that damage neurons and lead to Parkinson's disease (PD). In contrast, M2 microglia release neuroprotective factors and exert the effects of neuroprotection. Camptothecin (CPT), an extract of the plant Camptotheca acuminate, has been reported to have antiinflammation and antitumor effects. However the effect of CPT on microglia polarization and microgliamediated inflammation responses has not been reported. Therefore, we aim to explore the effect of CPT on microglia polarization and its underlying mechanism on neuroinflammation.

\section{Methods}

C57BL/6 mice (25-30 g) were injected LPS or PBS into the substantia nigra (SN). Open-Field Test and Immunohistochemistry were performed to test the dyskinesia of mice and the loss of neurons in the substantia nigra (SN). Microglia cell line BV-2, the neuroblastoma SH-SY5Y and dopaminergic neuron MN9D cell were cultured. Cytotoxicity assay, reverse transcription quantitative real-time polymerase chain reaction (RT-PCR), Western blot, ELISA and Immunofluorescence staining were performed. All results were presented with mean \pm SD.

\section{Results}

In vivo, CPT improved dyskinesia of mice, reduced the loss of neurons in the substantia nigra (SN) and inhibited neuro-inflammatory responses in LPS-injected mice. In vitro, CPT inhibited M1 polarization of microglia and promotes M2 polarization via the AKT/Nrf2/HO-1-NF-KB signal axis. Furthermore, CPT protected the neuroblastoma cell line SH-SY5Y and dopaminergic neuron cell line MN9D from neurotoxicity of mediated by microglia activation.

\section{Conclusion}

$\mathrm{CPT}$ regulates the microglia polarization phenotype via the AKT/Nrf2/HO-1-NF-KB signal axis, inhibits neuro-inflammatory responses and exerts neuroprotective effects in vivo and in vitro.

\section{Introduction}


Parkinson's disease (PD), the most common neurodegenerative disease seriously affects human health. PD is characterized by the loss of dopaminergic neurons in the substantia nigra (SN) of midbrain, and its clinical manifestations are motor dysfunction. At present, it is generally believed that environmental, genetic, physiological aging and other factors can cause PD [1,2]. The specific pathogenesis is not yet clear. Accumulated evidences have shown that neuroinflammation participated in the occurrence and development of PD $[3,4]$. Neuroinflammation has a two-way regulation effect. On the one hand, when the central nervous system is damaged by various pathogenic factors, immune cells are activated, and the resulting inflammatory response can kill harmful pathogens, remove abnormally accumulated proteins and cell fragments, and maintain damaged neurons, play a role in protecting neurons. On the other hand, when the inflammatory reaction continues, various harmful factors will be released and accumulate in the brain, such as inflammatory chemokines, reactive oxygen species, excitatory amino acid ions, etc., which cause damage to peripheral neurons and lead to PD further exacerbated [5-7]. Therefore, proper regulation of neuroinflammation is of great significance for alleviating PD.

Microglia, a type of immune cells that exist in the central nervous system (CNS), have the functions of immune monitoring, phagocytosis of debris, secretion of various factors and antigen presentation [8]. Microglia have three phenotypes: M0, M1 and M2. Under normal conditions, microglia are in the M0 phenotype. Once activated, microglia are polarized into M1 or M2 phenotype. M1, classic macrophage, produce pro-inflammatory mediators and chemokines to promote tissue defense and pathogen destruction. However, persistent M1 microglia continue to participate in the pathogenesis of PD and amplify neuronal damage caused by pathological stimuli and toxins, which in turn lead to more extensive damage to neighboring neurons. M2, replacement macrophages, can release CD206, Arg-1, Ym-1 and other molecules to promote wound healing and tissue repair. Contrary to M1, M2 is an anti-inflammatory phenotype [9-11]. Therefore, inhibiting M1 polarization in microglia and promoting M2 polarization are of great significance for inhibiting neuroinflammation and alleviating PD.

Camptothecin (CPT), a plant drug extracted from Camptotheca acuminate, has rich pharmacological effects such as antivirus, antitumor and changes in the keratinization process of the skin epidermis [12, 13]. CPT has a wide range of sources and is easy to extract. Most previous studies have devoted to the therapeutic effects of CPT on cancer. Recent some studies have found that CPT also plays a role in inflammation $[14,15]$. In vivo sepsis models, CPT can inhibit the expression of several inflammatory cytokines and rescue mortality caused by inflammation [16]. Studies showed that CPT at low concentration can inhibit the expression of topoisomerase 1 and the inhibition of topoisomerase 1 has been found to inhibit the expression of inflammatory genes $[17,18]$. It is known that NF-KB is closely related to the polarization of macrophages. Studies have also reported that CPT affects the activity of NF-KB $[19,20]$. However the effect of CPT on microglia polarization and microglia-mediated inflammation responses has not been reported. In the experiment, we aim to explore the effect of CPT on microglia polarization and its underlying mechanism on neuroinflammation.

\section{Materials And Methods}




\subsection{Reagents and Chemicals}

Camptothecin (CPT, purity $\geq 98 \%$ ) was bought from Pu Feide Biotechnology (chengdu, China). LPS (E. coli, Serotype 055:B5) and Dulbecco's modified Eagle's medium (DMEM) were obtained from BestBio (Shanghai, China). Fetal bovine serum (FBS) and horse serum (HS) were bought from Gibco (Grand Island, USA). TRIzol reagent was provided by Sigma-Aldrich (StLouis, U SA). The $0.05 \%$ trypsin was bought from Invitrogen (Carlsbad, USA).

\subsection{Animals and models}

Sixty male C57BL/6 mice (25-30 g) were purchased from Liaoning Changsheng Technology (Liaoning, China). Our experiment was recognized by the Institutional Animal Care and Use Committee of Jilin University (Changchun, China) (Permit Number: 2015047). During the experiment, we have done our best to reduce the suffering of animals. The PD mouse model was established. The experiment includes four groups: control group (which was injected PBS into the right SN), treated with CPT $(0.5 \mathrm{mg} / \mathrm{kg})$ group, LPS-injected group, LPS-injected treated with CPT $(0.5 \mathrm{mg} / \mathrm{kg})$ group. The mice were injected with LPS $(0.2 \mathrm{mg} / \mathrm{kg})$ or equal volume PBS into the right SN after anesthesia (stereotactic coordinates: dorsoventral $(\mathrm{DV})=-2.5 \mathrm{~mm}$, mediolateral $(\mathrm{ML})=-0.8 \mathrm{~mm}$ and anterior-posterior $(\mathrm{AP})=+0.5 \mathrm{~mm}$.). CPT was dissolved in PBS and given by gavage every two days. In addition, mice received CPT 3 days before surgery and a total of 24 days. Before the operation and on the 28th day after the operation, we measured the body weight of the mice. On the 24th day after the operation, we performed an open field test.

\subsection{Open-Field Test}

On the 24th day after LPS injection, the open field assay was performed to test the effect of the CPT on motor activity of mice. Mice were placed in a quiet, low-light box and allowed to adapt to the environment for $5 \mathrm{~min}$. The bottom area of the box was cleaned up prior to test to avoid the effect of previous test. The experimental mice were placed in the open field for $5 \mathrm{~min}$. The trajectory, total traveled distance and time in the center square within 5 min were recorded by the computer and software (Any-maze, Stoelting Co).

\subsection{Immunohistochemistry}

After stripped, the mouse midbrains were fixed in $4 \%$ formaldehyde and paraffin sectioned as described previously [21].The immune-histochemical processes were conducted using a Ultra-Sensitive S-P kit. The dopaminergic neurons and microglia in SNpc were marked using the anti-tyrosine hydroxylase $(\mathrm{TH})$ (1:800) and anti-ionized calcium-binding adaptor molecule-1 (IBA-1) (1:1000) (Abcam, Cambridge, UK).The TH- and IBA-1-positive cells were counted by five experimenters.

\subsection{Cell culture}

Microglia cell line BV-2, the neuroblastoma SH-SY5Y and dopaminergic neuron MN9D cell were obtained from the Cell Culture Center at the Institute of Basic Medical Sciences (Peking, China). The cells were cultured in DMEM medium which contained 10\% FBS (Gibco, Grand Island, NY, USA). The medium was 
changed every day and the cells were passaged when the confluence of the cells reached $70-80 \%$. In the experiment, cells were treated with CPT for $1 \mathrm{~h}$, stimulated with LPS $(1 \mu \mathrm{g} / \mathrm{mL})$ for different times, and then collected for measurement.

\subsection{Reverse transcription quantitative real-time polymerase chain reaction (RT-PCR)}

Total RNA of the cells and mouse midbrains were collected with the RNA extraction kit (Takara Biotechnology, Ltd., Kyoto, Japan). After detection of RNA concentration, $3 \mu \mathrm{g}$ RNA was reversetranscribed into cDNA with the PrimerScript ${ }^{\circledR}$ 1st Strand cDNA Synthesis Kit (Sigma-Aldrich, St. Louis, MO, USA). After that, the mRNA levels of M1 markers (IL-6, TNF-a, COX-2 and iNOS) and M2 markers (CD206, Ym-1 and Arg-1) were examined with the SYBR Green Kit (South San Francisco, CA, USA) and the results were analyzed relative to $\beta$-actin using the $2^{-\triangle \Delta C t}$ means. The sequences of the factors were shown in Table 1, which referred to previous studies [22].

Table 1

The primer sequences for RT-PCR.

\begin{tabular}{|c|c|}
\hline Gene & sequences \\
\hline \multirow[t]{2}{*}{ IL-6 } & (F) 5'- CCAGAAACCGCTATGAAGTTCC-3' \\
\hline & (R) 5'- GTTGGGAGTGGTATCCTCTGTGA-3' \\
\hline \multirow[t]{2}{*}{$T N F-a$} & (F) 5'-GCAACTGCTGCACGAAATC-3' \\
\hline & (R) 5'-CTGCTTGTCCTCTGCCCAC-3' \\
\hline iNOS & (F) 5'-GAACTGTAGCACAGCACAGGAAAT-3' \\
\hline \multirow[t]{3}{*}{$\operatorname{cox}-2$} & (R) 5'-CGTACCGGATGAGCTGTGAAT-3' \\
\hline & (F) 5'-CAGTTTATGTTGTCTGTCCAGAGTTTC-3' \\
\hline & (R) 5'-CCAGCACTTCACCCATCAGTT-3' \\
\hline $\operatorname{Arg}-1$ & (F) 5'-GTGAAGAACCCACGGTCTGT-3' \\
\hline$Y m-1$ & (R) 5'-GCCAGAGATGCTTCCAACTG-3' \\
\hline CD206 & (F) 5'-CAGGGTAATGAGTGGGTTGG-3' \\
\hline \multirow[t]{5}{*}{$\beta$-actin } & (R) 5'-CACGGCACCTCCTAAATTGT-3' \\
\hline & (F) 5'-CTTCGGGCCTTTGGAATAAT-3' \\
\hline & (R) 5'-TAGAAGAGCCCTTGGGTTGA-3' \\
\hline & (F) 5'-GTCAGGTCATCACTATCGGCAAT-3' \\
\hline & (R) 5'-AGAGGTCTTTACGGATGTCAACGT-3' \\
\hline
\end{tabular}

\subsection{Western blot}


Total proteins of the cells and mouse midbrains were obtained with a protein assay kit and then quantified into $40 \mu \mathrm{g}$ per $15 \mu \mathrm{l}$ using SDS and P0013B lysate (Beyotime Inst. Biotech, Beijing, China) for western blot assay. A total of $40 \mu \mathrm{g}$ of proteins were subjected to $8 \%, 12 \%$ and $15 \%$ SDS-PAGE and transferred onto PVDF membranes (Millipore, Billerica, MA, USA). After blocked with 5\% skim milk, membranes were incubated for $12 \mathrm{~h}$ with primary antibodies against TH(1:500), IBA-1 (1:500) (Abcam, Cambridge, UK)), COX-2 (1:1000), iNOS (1:1000), phos-AMPK (1:1000), AMPK (1:1000), phos-AKT (1:1000), AKT (1:3000), phos-NF-kB p65 (1:3000), NF-KB p65(1:3000) (Abcam, Cambridge, UK), Nrf2(1:1000), HO-1(1:2000) and $\beta$-actin (1:5,000) (Santa Cruz, CA, USA). Next the membranes were washed six times with TBST ( 5 min per time) and incubated for $2 \mathrm{~h}$ against the secondary antibodies goat anti-mouse (1:4000) or goat anti-rabbit (1:4000). Then membranes were again washed six times with TBST 5 min per time). After then, the proteins were measured with ECL Luminous liquid (Beyotime Inst. Biotech, Beijing, China).

\subsection{Cytotoxicity assay}

The effects of CPT on cell viability were tested using CCK-8 method. After cultured for $24 \mathrm{~h}$, the cells were incubated with DMSO and different concentrations CPT $(0-2 \mu \mathrm{M})$ for $20 \mathrm{~h}$, and then CCK-8 diluent was added to culture medium and cultured for $3 \mathrm{~h}$. After that, the absorbance was examined with a microplate reader at $450 \mathrm{~nm}$.

\subsection{ELISA}

The cells were cultured in the 24-well plates. After incubation with CPT for $1 \mathrm{~h}$ and stimulated with LPS $(1 \mu \mathrm{g} / \mathrm{mL})$ for $24 \mathrm{~h}$, the protein expression of TNF- $\mathrm{a}$ and IL-6 in the supernatant was examined with the ELISA kits (R\&D Systems, Abingdon, UK).

\subsection{Immunofluorescence staining}

Immunofluorescence staining was performed to determine the nuclear translocation of the NF-kB p65 in LPS-exposed BV-2 cells. The nuclear location of the NF-kB p65 is marked by anti-NF-kB p65 antibodies (1:1000) (Abcam, Cambridge, UK).

\subsection{Data analyses}

Results were presented with mean \pm SD, and analyzed with SPSS 13.0 software package (SPSS Inc., Chicago, USA). The differences were evaluated with the one-way analysis of variance (ANOVA) method. The $p<0.05$ was considered to be significant and $p<0.01$ was considered to be markedly significant.

\section{Results}

\subsection{CPT treatment alleviates the weight loss and behavioral disorder of LPS-injected PD mice}


Unilateral injection of LPS into the SN can cause weight loss and motor dysfunction in mice. In order to prove the protective effect of CPT, we studied the effect of CPT treatment on weight loss and motor behavior disorders in the LPS-injected PD mouse model. The experimental process is executed as shown in Fig. 1A. On the 28th day after LPS injection, the weight change of the mice was measured. The results showed that LPS injection caused weight loss in mice, and CPT treatment could significantly improve LPS-induced weight loss in the LPS-injected PD mouse model (Fig. 1B). On the 24th day after LPS injection, we tested the athletic ability of mice through an open field experiment. The results showed that LPS injection caused the distance moving in the open field and time in the center less, and CPT treatment could improve this phenomenon (Fig. 1C-E). These results illustrated that CPT treatment alleviates the weight loss and behavioral disorder of LPS-injected PD mouse model.

Figure 1. CPT treatment alleviates the weight loss and behavioral disorder of LPS-injected PD mouse model. (A) Experiment procedure. Mice were injected with LPS $(0.2 \mathrm{mg} / \mathrm{kg})$ or equal volume PBS into the right SNpc after anesthesia and treated every two days with CPT $(0.5 \mathrm{mg} / \mathrm{kg}) 3$ days before surgery and a total of 24 days. (B) The weight change of mice during the experiment. Before the operation and on the 28th day after the operation, the body weight of mice was measured. (C-E) The locomotor activity of mice was tested using the open field assay. Results are shown as means $\pm S D(n=5) .{ }^{\#} p<0.01$ vs. the notreatment (NT) group; $* * p<0.01$ vs. the LPS-injected group.

\subsection{CPT treatment decreases dopaminergic neurons degeneration in LPS- injected PD mice}

The main pathological feature of PD is the degeneration of dopaminergic neurons. To explore protective effect of CPT, we studied the effect of CPT on the dopaminergic neurons in LPS- injected PD mice. On the 28th day after LPS injection, we obtained the midbrain of mice and examined the number of TH-positive cells using immunohistochemistry method. Results showed that LPS injection caused a significant decrease of midbrain dopaminergic neurons in LPS- injected PD mice, and CPT treatment could protect the neurons from the damage caused by LPS (Fig. 2A, B). The protein level of TH was examined using western blot. The results also confirmed the protective effect of CPT from a protein perspective (Fig. 2C). These results illustrated that CPT treatment decreases dopaminergic neurons degeneration in LPSinjected PD mice.

Figure2. CPT treatment decreases dopaminergic neurons degeneration in LPS- injected PD mice. Experiment mice were anesthetized and sacrificed to obtain the midbrain on the 28th day after LPS injection. (A, B) The numbers of TH-positive cells in the $\mathrm{SN}$ were examined using immunohistochemistry (the scale bar represents $200 \mu \mathrm{m}$ ). (C) The protein level of TH in midbrain was examined using western blot. Results are shown as means \pm SD $(n=5) .{ }^{\# \#} p<0.01$ vs. the no-treatment (NT) group; ${ }^{*} p<0.01$ vs. the LPS-injected group.

\subsection{CPT treatment inhibits inflammatory response and regulates microglia polarization in LPS- injected PD mice}


To further confirm neuroprotection of CPT and its mechanism, we studied the effect of CPT on inflammatory response and microglia polarization in LPS- injected PD mouse model. On the 28th day after LPS injection, we obtained the midbrain of mice. AKT/Nrf2/HO-1-NF-KB signal axis was detected by western blot. The results showed that CPT activated AKT/Nrf2/HO-1 and inhibited NF-KB pathways (Fig. 3A-C). Then we detected the mRNA levels of M1 markers (IL-6, TNF-a, iNOS and COX-2) and M2 markers (Ym-1, CD206 and Arg-1) in the midbrain of mice by RT-PCR. Results showed that CPT inhibited release of M1 markers and promoted release of M2 markers (Fig. 3D-J). These results illustrated that CPT treatment inhibits inflammatory response and regulates microglia polarization via AKT/Nrf2/HO-1-NF-KB signal axis in LPS- injected PD mouse model.

Figure 3. CPT treatment inhibits inflammatory response and regulates microglia polarization in LPSinjected PD mice. On the 28th days after modeling, the midbrain of mice was peeled off and ground. (A-C) AKT/Nrf2/HO-1-NF-KB signal axis was detected using western blot. (D-J) The mRNA levels of M1 markers (IL-6, COX-2, iNOS and TNF-a) and M2 markers (Ym-1, CD206 and Arg-1) were detected using RT-PCR. Results are shown as means $\pm S D(n=5) .{ }^{\# \#} p<0.01$ vs. the no-treatment (NT) group; ${ }^{\star *} p<0.01$ vs. the LPS-exposed group.

\subsection{CPT inhibits the inflammatory response in LPS-exposed BV-2 cells}

To further elucidate the role of CPT on neuroinflammation, we studied the anti-inflammatory effects of CPT on BV-2 cells. First of all,we studied the potential cytotoxic effect of CPT on BV-2 cells. Results showed that CPT for $0-1 \mu \mathrm{M}$ did not affect the viability of BV-2 (Fig. 4A). Next, we examined the effect of $\mathrm{CPT}$ treatment on MI, M2 microglia markers release. The cells were pretreated with CPT for $1 \mathrm{~h}$ and stimulated with LPS for $12 \mathrm{~h}$ (mRNA) or $24 \mathrm{~h}$ (protein). Then the mRNA and protein levels of M1 and M2 markers were tested by RT-PCR, ELISA and western blot techniques. Results showed that CPT treatment inhibited the expression of MI markers (IL-6 (Fig. 4B, I), TNF-a (Fig. 4C, J), iNOS (Fig. 4D, K, M) and COX-2 (Fig. 4E, L, M)) and promoted the expression of M2 markers (Arg-1 (Fig. 4F, M, N), Ym-1 (Fig. 4G, M,P) and CD206 (Fig. 4H, M, O)). These results illustrated that CPT inhibited the inflammatory response in LPSexposed BV-2 cells.

Figure4. CPT attenuates the inflammatory response in LPS-exposed BV-2 cells. (A) The viability of BV-2 cells was measured using CCK-8 assay. The cells were pretreated with CPT $(0.5 \mu \mathrm{M}$ and $1 \mu \mathrm{M})$ for $1 \mathrm{~h}$ and then treated with LPS $(1 \mu \mathrm{g} / \mathrm{mL})$ for $12 \mathrm{~h}$ (mRNA) and $24 \mathrm{~h}$ (protein). (B-H) The mRNA levels of M1 microglia markers (IL-6, TNF-a, iNOS and COX-2) and M2 microglia markers (Ym-1, CD206 and Arg-1) were detected by RT-PCR. (I-P) The protein levels of M1 microglia markers and M2 microglia markers were measured using ELISA (IL-6 and TNF-a) and western blot (COX-2, iNOS, Arg-1, CD206 and Ym-1). Results are shown as means \pm SD $(n=5) .{ }^{\#} p<0.5$ and ${ }^{\# \#} p<0.01$ vs. the no-treatment (NT) group; ${ }^{* *} p<0.01$ vs. the LPS-exposed group.

\subsection{CPT inhibits activation of NF-KB pathway in LPS- exposed BV-2 cells}


NF-kB pathway, a key pathway of inflammation, affects the production of many pro-inflammatory mediators. To investigate the mechanism which CPT regulates the polarization of M1 and M2 microglia, we detected the effect of CPT on the activation of NF-KB pathway. BV-2 cells were pretreated with CPT for $1 \mathrm{~h}$ and stimulated with LPS for another $1 \mathrm{~h}$. Then phosphorylation of $\mathrm{IKB}, \mathrm{NF}-\mathrm{kB}$ p65 and degradation of IKB were detected using western blot. After that, we also examined the nuclear positioning of NF-KB p65 by immunofluorescence. Results showed that CPT inhibited phosphorylation of NF-kB p65 (Fig. 5A, B), IKB (Fig. 5A, C) and degradation of IKB (Fig. 5A, D) and nuclear translocation of NF-KB p65 (Fig. 5E, F). These results illustrated that CPT inhibits activation of NF-KB in LPS-exposed BV-2 cells.

Figure 5. CPT inhibits activation of NF-KB in LPS-exposed BV-2 cells. BV-2 cells were pretreated with CPT $(0.5 \mu \mathrm{M}$ and $1 \mu \mathrm{M})$ for $1 \mathrm{~h}$ and stimulated with LPS $(1 \mu \mathrm{g} / \mathrm{mL})$ for another $1 \mathrm{~h}$. (A)The protein levels of IKB, NF-KB p65 and their phosphorylation were detected by western blot. (B) The levels of phos-NF-кB p65 were analyzed relative to NF-KB p65. (C-D) The levels of IKB and phos-IKB were analyzed relative to $\beta$ actin. (E-F) The nuclear translocation level of NF-KB p65 was examined by immunofluorescence staining (the scale bar represents $200 \mu \mathrm{m})$. Results are shown as means \pm SD $(n=5) .{ }^{\sharp \#} p<0.01$ vs. the untreated group (NT); ${ }^{*} p<0.01$ vs. the LPS-exposed group.

3.6 CPT promotes phosphorylation of AKT, activation of Nrf2 and up-regulates the expression of $\mathrm{HO}-1$ in BV-2 cells

To further clarify the mechanism of CPT anti-inflammatory, we studied the effect of CPT on AKT, Nrf2 and HO-1 inflammation pathways. After the cells were treated with CPT $(0,0.25,0.5$ and $1 \mu \mathrm{M})$ for $3 \mathrm{~h}$, the protein levels of phos-AKT, HO-1, nuclear-nrf2 and Cytoplasm-nrf2 were detected by western blot. Results showed that CPT treatment promoted phosphorylation of AKT, activation of Nrf2 and up-regulated protein level of HO-1 (Fig. 6A-D). Then we pretreated cells with MK2206 (an AKT inhibitor, $10 \mu \mathrm{M}$ ) for $4 \mathrm{~h}$ and studied the effect of CPT on activation of Nrf2 using western blot. Results showed that MK2206 inhibited the promotion effect of CPT on the protein level of nuclear-nrf2 (Fig. 6E-F). We pretreated cells with RA (a nrf2 inhibitor, $5 \mu \mathrm{M}$ ) for $4 \mathrm{~h}$ and studied the effect of CPT on protein level of HO-1. Results showed that RA inhibited the effect of CPT on up-regulation of HO-1 (Fig. 6G-H). These results illustrated that CPT promotes AKT/Nrf2 / HO-1 signaling pathways in BV-2 cells.

Figure 6. CPT promotes phosphorylation of AKT, activation of Nrf2 and up-regulates the expression of HO-1. (A-D) After BV-2 cells were treated with CPT $(0,0.25,0.5$ and $1 \mu \mathrm{M})$ for $3 \mathrm{~h}$, the phosphorylation of AKT, the protein levels of nuclear-nrf2, Cytoplasm-nrf2 and HO-1 were examined using western blot. (E-F) After the cells were treated with MK2206 (an AKT inhibitor, $10 \mu \mathrm{M}$ ) for $4 \mathrm{~h}$ and CPT ( $1 \mu \mathrm{M})$ for another $3 \mathrm{~h}$, the protein levels of phos-AKT and nuclear-nrf2 were determined by western blot. (G-H) After BV-2 cells were treated with RA (a nrf2 inhibitor, $5 \mu \mathrm{M}$ ) for $4 \mathrm{~h}$ and CPT $(1 \mu \mathrm{M})$ for another $3 \mathrm{~h}$, the protein levels of nuclear-nrf2 and HO-1 were determined by western blot. Results are shown as means \pm SD $(n=5) .{ }^{\#} p<$ 0.01 vs. the no-treatment (NT)group; ${ }^{\&} p<0.01$ vs. the CPT-treated group. 


\subsection{CPT regulates microglial polarization via AKT/ Nrf2/HO- 1-NF-KB signal axis}

We pretreated cells with SnPP IX (a HO-1 inhibitor, $40 \mu \mathrm{M}$ ) for $3 \mathrm{~h}$ and studied the effect of CPT on NF-KB pathway activation. Results showed that SnPP IX can reverse the effect of CPT on inhibition of NF-KB pathway activation (Fig. 7A, B). Then we pretreated BV-2 cells with different inhibitors (MK2206 for $4 \mathrm{~h}$, RA for $4 \mathrm{~h}$ or SnPP IX for $3 \mathrm{~h}$ ) and studied the effect of CPT on microglial polarization. Results showed that the inhibitors (MK2206, RA and SnPP IX) can reverse the regulatory effect of CPT on the release of MI markers (IL-6, TNF-a, COX-2 and iNOS) (Fig. 7C-F) and M2 markers (CD206, Ym-1 and Arg-1) (Fig. 7GI). The above results illustrated that CPT regulates microglial polarization via AKT/Nrf2/HO-1-NF-KB signal axis.

Figure 7. CPT regulates microglial polarization via AKT/ Nrf2/HO-1-NF-kB signal axis. (A) After the cells were treated with SnPP IX (a HO-1 inhibitor, $40 \mu \mathrm{M})$ for $3 \mathrm{~h}$ and CPT $(1 \mu \mathrm{M})$ for another $3 \mathrm{~h}$, the protein level of HO-1 was examined by western blot. (B) After SnPP IX treatment, the effect of CPT on NF-KB activation was detected by western blot. (C-I) The cells were treated with different inhibitors (MK2206 for $4 \mathrm{~h}$, RA for $4 \mathrm{~h}$ or SnPP IX for $3 \mathrm{~h}$ ) and CPT $(1 \mu \mathrm{M})$ for $1 \mathrm{~h}$, then stimulated with LPS for $12 \mathrm{~h}$. The mRNA levels of M1 markers (IL-6, COX-2, iNOS and TNF-a) and M2 markers (CD206, Ym-1 and Arg-1) were examined using RT-PCR. Results are shown as means $\pm S D(n=5) .{ }^{\# \#} p<0.01$ vs. the no-treatment (NT) group; ${ }^{* *} p<0.01$ vs. the LPS-exposed group; ${ }^{s} p<0.05$ and ${ }^{s} p<0.01$ vs. the LPS + CPT-treated group.

3.8 CPT exerts a neuroprotective effect in SHSY5Y and MN9D cells by regulating the polarization of microglia

To confirm the effect of CPT on neuron, we studied the effect of CPT-treated BV2 cell supernatant on neuron viability. Firstly, BV-2 cells were preprocessed with CPT $(0.25 \mu \mathrm{M}, 0.5 \mu \mathrm{M}$ and $1 \mu \mathrm{M})$ for $1 \mathrm{~h}$ and stimulated with LPS $(1 \mu \mathrm{g} / \mathrm{mL})$ for another $3 \mathrm{~h}$. Then we changed the medium and cultured the cells for $18 \mathrm{~h}$ under the new medium environment. After that, the supernatant is collected and the conditioned medium was prepared with the supernatant and complete medium in a one-to-one ratio. Then the SHSY5Y and MN9D cells were cultured with the conditioned medium for $18 \mathrm{~h}$. After that, the viability of the SHSY5Y and MN9D cells was measured using CCK-8. The results showed that CPT exerts a neuroprotective effect in SHSY5Y (Fig. 8A) and MN9D (Fig. 8B) cells by regulating the polarization of microglia.

Figure 8. CPT exerts a neuroprotective effect in SHSY5Y and MN9D cells by regulating the polarization of microglia. The SHSY5Y and MN9D cells were cultured with the conditioned medium for $18 \mathrm{~h}$. The viability of the SHSY5Y (A) and MN9D (B) cells was measured using CCK-8. Results are shown as means \pm SD ( $n$ = 5). ${ }^{\# \#} p<0.01$ vs. the no-treatment (NT) group; ${ }^{* *} p<0.01$ vs. the LPS-exposed group.

\section{Discussion}


PD, the second largest neurodegenerative disease seriously affects the physical and mental health of elderly people. Clinically, PD patients have severe motor impairments and massive loss of dopaminergic neurons in the $\mathrm{SN}$ of midbrain [23]. The etiology of PD is still unclear, and the accumulated evidences demonstrate that neuroinflammation plays an important role in the occurrence and development of PD. When neuroinflammation occurs, the immune cells, mainly microglia are over-activated to release proinflammatory mediators, resulting in the degeneration of peripheral neurons [24-26]. Therefore, inhibition of neuro-inflammation is also considered to be a target for the treatment of PD. LPS, a component of the cell wall of Gram-negative bacteria can induce inflammation response. Studies have demonstrated that the injection of LPS into the SN of rats can induce PD symptoms [27, 28]. In the experiment, we found that mice injected with LPS in the SN had PD symptoms such as weight loss and motor dysfunction compared with control mice. Further research found that dopaminergic neurons decreased in the $\mathrm{SN}$ of LPS-injected mice. Our research also found that CPT could relieve PD symptoms and improve the damage of neurons of LPS-injected mice. The results prompted that CPT has a neuroprotective effect.

Microglia, immune cells in the CNS, is the main participants of neuro-inflammatory response. Studies have reported that there are numerous microglia activated abnormally in the midbrain of PD patients and PD model animals [29, 30]. BV-2 cells, microglial cell lines, have been widely used to study the function of microglia due to the similarity to microglia [31,32]. To further study the neuroprotective effect of CPT and its mechanism, we studied the effect of CPT on microglia inflammation using BV-2 cells. In the experiment, we found that CPT treatment can inhibit the release of M1 markers and promote the release of M2 markers. We also found that CPT exhibited this effect in LPS-injected mice. The results prompted that CPT inhibits the polarization of microglia to the pro-inflammatory M1 and promotes to the antiinflammatory $\mathrm{M} 2$, thereby exerting an anti-inflammatory effect.

$\mathrm{NF}-\mathrm{KB}$, a classic inflammatory pathway, is involved in cellular inflammation and many nervous system diseases. Studies have reported that NF-KB can regulate the transcription of various pro-inflammatory mediators and considered to be a target for inflammatory diseases [33,34]. There are also reports that NF-KB pathway is closely related to the polarization of immune cells [35]. Under normal conditions, NF-KB p65 is present in the cytoplasm and binds to IKB subunit. Once activated, IKB subunit degrades and NFKB p65 undergoes nuclear translocation and phosphorylation[36]. In the experiment, we found that CPT can inhibit the degradation of IKB and nuclear translocation of NF-KB p65 in LPS-exposed BV-2 cells. The results prompted that $\mathrm{CPT}$ inhibits microglia inflammation by repressing the activation of the NF-KB pathway.

AKT pathway, or PI3K-AKT pathway is involved in fundamental cellular processes including protein synthesis, proliferation and survival. AKT signaling has been implicated in various inflammation responds [37, 38]. Nrf2 is a key transcription factor regulating oxidative stress. Studies found that activated-nrf2 enter into the nuclear and regulates transcription of many inflammatory factors. $\mathrm{HO}-1$ is a key anti-inflammatory protein downstream of $\operatorname{Nrf2}[39,40]$. In the experiment, we found that CPT treatment can activate the AKT pathway, promote activation of Nrf2 and up-regulate the expression of HO-1. To further study anti-inflammatory effect of CPT on microglia, we treated BV-2 cells with MK2206 
(an AKT inhibitor), RA (a Nrf2 inhibitor) or SnPP IX (a HO-1 inhibitor) respectively. The results showed that after blocking the AKT pathway with MK2206, the effect of CPT on Nrf2 nuclear transcription was suppressed. These indicate that CPT promotes activation of Nrf2 through activating AKT in microglia. At the same time, RA and SnPP IX treatment also demonstrated the regulatory effect of CPT on inflammatory pathways. In addition, we also explored the effect of CPT on the release of M1 and M2 markers in microglia after BV2 cells treated with MK2206, RA or SnPP IX. The results showed that MK2206, RA or SnPP IX treatment reversed the regulatory effect of CPT on M1 and M2 markers to a certain extent. The results prompted that CPT regulates the M1 and M2 polarization of microglia through AKT/Nrf2/HO-1-NF-KB signaling axis. The experiments in vivo also confirmed this.

To explore the neuroprotective effect of CPT, we pretreated BV-2 cells with CPT and stimulated with LPS to induce microglial activation. Then we change the fresh medium for $18 \mathrm{~h}$ and obtain conditioned medium. Next we studied the effect of conditioned medium on viability of SHSY5Y and MN9D neuronal cell lines. The results showed that CPT could inhibit microglial activation-mediated neurotoxicity and protect neurons.

Figure 9. Camptothecin regulates microglia polarization and exerts neuroprotective effects via the AKT/Nrf2/HO-1-NF-KB signal axis.

\section{Conclusions}

In conclusion, our study found for the first time that CPT inhibits microglial M1 polarization and promotes M2 polarization through the AKT/Nrf2/HO-1-NF-KB signal axis, thereby inhibiting neuroinflammation and exerting the effect of neuroprotection in vivo and in vitro (Fig. 9). This experiment would provide new ideas for the treatment of inflammation-mediated PD. Combining its extensive pharmacological effects and easily available properties, CPT is expected to be further developed and studied. Future research will also focus more on the potential therapeutic role of CPT in inflammatory diseases and assess the possibility of being developed as anti-inflammatory drugs.

\section{Abbreviations}

AKT, protein kinase B; Arg-1, Arginase 1; CD206, Mannose receptor; COX-2, Cyclooxygenase-2; CNS, Central nervous system; HO-1, Hypoeretin-1; iNOS, Induced nitric oxide synthase; IL-6, Interleukin-6; PD, NFkB, nuclear factor kappa B; Nrf2, nuclear factor erythroid 2-related factor 2; Parkinson's disease; RA, retinoic acid; SN, Substantia nigra; SnPP IX, tin protoporphyrin-IX; TNF-a, Tumor necrosis factor-a; Ym-1, Chitinase-3-Like-3;

\section{Declarations}

\section{Ethics approval and consent to participate}


This article does not contain any studies with human participants. The experiment was recognized by the Institutional Animal Care and Use Committee of Jilin University (Changchun, China) (Permit Number: 2015047).

\section{Consent for publication}

Not applicable

\section{Availability of data and materials}

All data generated or analysed during this study are included in this published article [and its supplementary information files].

\section{Competing interests}

The authors declare that they have no competing interests.

\section{Funding}

This work was funded by National Natural Science Foundation of China (project No. 31772547, 31702211) Jilin Scientific and Technological Development Program (project No. 20200703011ZP).

\section{Author Contributions}

Dewei He and Dianfeng Liu accomplished most of the experiments, analyzed the results and wrote the manuscript. Shoupeng Fu designed this study. Ang Zhou and Xiyu Gao took part in various aspects of the study and read and revised first draft. Yufei Zhang, Yingchun Su, Bingxu Huang and Jian Du also participated in the research. All authors read and approved the final manuscript.

\section{Acknowledgments}

Not applicable.

\section{References}

1. Lees AJ. Impact Commentaries. The relevance of the Lewy Body to the pathogenesis of idiopathic Parkinson's disease: accuracy of clinical diagnosis of idiopathic Parkinson's disease. Journal of Neurology Neurosurgery Psychiatry. 2012;83:954.

2. Dauer W, Przedborski S. Parkinson's Disease. Neuron 2003, 25. 
3. Hirsch EC, Vyas S, Hunot S. Neuroinflammation in Parkinson's disease. Parkinsonism Related Disorders. 2012;18:210-2.

4. More SV, Kumar H, Kim IS, Song SY, Choi DK. Cellular and Molecular Mediators of Neuroinflammation in the Pathogenesis of Parkinson's Disease. Mediators Inflamm. 2013;2013:112.

5. Anna L, Bartels, Klaus L. Leenders: Neuroinflammation in the pathophysiology of Parkinson's disease: Evidence from animal models to humanin vivostudies with [11C]-PK11195 PET. Movement Disorders 2007.

6. Armando DV, Antonio G, Giovanni F, Maurizio I, Marco DV. Parkinson's Disease: Autoimmunity and Neuroinflammation. Autoimmunity Reviews 2016, 15.

7. Chung YC, Ko HW, Bok E, Park ES, Jin BK. The role of neuroinflammation on the pathogenesis of Parkinson's disease. Bmb Reports. 2010;43:225-32.

8. Perry VH, Nicoll JAR, Holmes C. Microglia in neurodegenerative disease. Nature Reviews Neurology. 2010;6:193-201.

9. Tang Y, Le W. Differential Roles of M1 and M2 Microglia in Neurodegenerative Diseases. Mol Neurobiol. 2016;53:1181-94.

10. Zhang B, Wei Y-Z, Wang G-Q, Li D-D, Shi J-S, Zhang F. Targeting MAPK Pathways by Naringenin Modulates Microglia M1/M2 Polarization in Lipopolysaccharide-Stimulated Cultures. Frontiers in Cellular Neuroscience 2019, 12.

11. Eugene B, Cheul CY, Ki-Suk K, Hwan BH, Won-Ho S, Jin BK. Modulation of M1/M2 polarization by capsaicin contributes to the survival of dopaminergic neurons in the lipopolysaccharide-lesioned substantia nigra in vivo. Exp Mol Med. 2018;50:76-.

12. Ran $X$, Zhang G, Sheng $L$, Wang J: Characterization and antitumor activity of camptothecin from endophytic fungus $<\mathrm{i}>$ Fusarium solani $</ \mathrm{i}>$ isolated from $<\mathrm{i}>$ Camptotheca acuminate $</ \mathrm{i}>$. African Health Sciences 2017, 17:566-.

13. Koo OM, Rubinstein I, Onyüksel H. Camptothecin, Rheumatoid Arthritis. Pharm Res. 2011;28:776-87.

14. QUINAZOLINE DERIVATIVES. US

Barker A. John: QUINAZOLINE DERIVATIVES. US.

15. Cashman J, Burt HM, Springate C, Gleave J, Jackson JK. Camptothecin-loaded films for the prevention of postsurgical adhesions. Inflamm Res. 2004;53:355-62.

16. Pan P, Chen J, Li X, Li M, Yu H, Zhao JJ, Ni J, Wang X, Sun H, Tian S, et al. Structure-Based Drug Design and Identification of H2O-Soluble and Low Toxic Hexacyclic Camptothecin Derivatives with Improved Efficacy in Cancer and Lethal Inflammation Models in Vivo. J Med Chem. 2018;61:861324.

17. Jin J, Xu W, Wan B, Wang X, Zhou Z, Miao Y, Lv T, Song Y. Topotecan Alleviates LipopolysaccharideMediated Acute Lung Injury Via the NF-KB Signaling Pathway. J Surg Res. 2019;235:83-92. 
18. Rialdi A, Campisi L, Zhao N, Lagda AC, Pietzsch C, Ho JSY, Martinez-Gil L, Fenouil R, Chen X, Edwards M. Topoisomerase 1 inhibition suppresses inflammatory genes and protects from death by inflammation. Science. 2016;352:1074-4.

19. Kühnemuth B, Mühlberg L, Schipper M, Griesmann H, Neesse A, Milosevic N, Wissniowski T, Buchholz M, Gress TM, Michl P. CUX1 modulates polarization of tumor-associated macrophages by antagonizing NF-KB signaling. Oncogene. 2015;34:177-87.

20. Deng X, Zhang P, Liang T, Deng S, Zhu L. Ovarian cancer stem cells induce the M2 polarization of macrophages through the PPARy and NF-KB pathways. Int J Mol Med. 2015;36:449.

21. He D, Huang B, Fu S, Li Y, Xin R, Liu Y, Chen G, Liu J, Liu D. Tubeimoside I Protects Dopaminergic Neurons Against Inflammation-Mediated Damage in Lipopolysaccharide (LPS)-Evoked Model of Parkinson's Disease in Rats. Int J Mol Sci. 2018;19:2242-.

22. Liu B, Huang B, Hu G, He D, Liu D. Isovitexin-Mediated Regulation of Microglial Polarization in Lipopolysaccharide-Induced Neuroinflammation via Activation of the CaMKK $\beta / A M P K-P G C-1 a$ Signaling Axis. Front Immunol. 2019;10:2650.

23. Lang AE, Lozano AM. Parkinson's Disease. Lancet. 1998;386:896-912.

24. Ouchi Y, Yagi S, Yokokura M, Sakamoto M. Neuroinflammation in the living brain of Parkinson's disease. Parkinsonism Relat Disord. 2009;15(Suppl 3):200-4.

25. Calabrese V. Santoro, Aurelia, Monti, Daniela, Crupi, Rosalia, Di, Paola: Aging and Parkinson's Disease: Inflammaging, neuroinflammation and biological remodeling as key factors in pathogenesis. Free Radical Biology \& Medicine the Official Journal of the Oxygen Society 2018.

26. Rodrigues LS, Fagotti J, Targa ADS, Noseda ACD, Lima MMS. Potential new therapies against a toxic relationship: neuroinflammation and Parkinson's disease. Behav Pharmacol. 2019;30:676.

27. Machado A, Herrera AJ, Venero JL, Santiago M, de Pablos RM, Villaran RF, Espinosa-Oliva AM, Arguelles S, Sarmiento M, Delgado-Cortes MJ, et al. Inflammatory Animal Model for Parkinson's Disease: The Intranigral Injection of LPS Induced the Inflammatory Process along with the Selective Degeneration of Nigrostriatal Dopaminergic Neurons. ISRN Neurol. 2011;2011:476158.

28. Santiago RM, Barbieiro J, Lima MMS, Dombrowski PA, Andreatini R, Vital MABF. Depressive-like behaviors alterations induced by intranigral MPTP, 6-OHDA, LPS and rotenone models of Parkinson\"s disease are predominantly associated with serotonin and dopamine. Prog Neuropsychopharmacol Biol Psychiatry. 2010;34:0-1114.

29. Yoon S, Kim, Tong J. Microglia, major player in the brain inflammation: their roles in the pathogenesis of Parkinson's disease. Experimental \& molecular medicine 2006.

30. A histological study of STN-DBS treated brain of a Parkinson's disease patient: 2. Distribution of astroglia and microglia. In Functional Neurosurgery: Meeting of the Japan Society for Stereotactic \& Functional Neurosurgery. 2005.

31. Hong L, Shao S, Wang G, Anatomy DO, University GM. Effect of purmorphamine on Parkinson's disease-related Nurr1 gene expression in BV2 cells. Chinese Journal of Neuroimmunology \& Neurology 2016. 
32. Kristensen SL, Hedtjärn M, Schrattenholz A, Henn A, Pörzgen PP, Leist M. The suitability of BV2 cells as alternative model system for primary microglia cultures or for animal experiments examining brain inflammation. Altex. 2009;26:83.

33. Ghosh S, May MJ, Kopp EB. NF-KB AND REL PROTEINS: Evolutionarily Conserved Mediators of Immune Responses. Annu Rev Immunol. 1998;16:225-60.

34. Li Q, Verma IM. NF-kappaB regulation in the immune system. Nat Rev Immunol. 2002;2:725.

35. Flavell RA, Sanjabi S, Wrzesinski SH, Licona-Limón P. The polarization of immune cells in the tumour environment by TGF $\beta$. Nat Rev Immunol. 2010;10:554-67.

36. Baldwin AS. THE NF-kB AND IкB PROTEINS: New Discoveries and Insights. Annu Rev Immunol. 1996;14:649-81.

37. Manning BD, Cantley LC. AKT/PKB Signaling: Navigating Downstream. 2007.

38. Zhao Y, Zhang Q, Xi J, Xiao B, Li Y, Ma C. Neuroprotective effect of fasudil on inflammation through $\mathrm{PI} 3 \mathrm{~K} / \mathrm{Akt}$ and Wnt/ $\beta$-catenin dependent pathways in a mice model of Parkinson's disease. International Journal of Clinical Experimental Pathology. 2015;8:2354.

39. Kim EN, Ji HL, Min YK, Ban TH, Choi BS. Resveratrol, an Nrf2 activator, ameliorates aging-related progressive renal injury. Aging. 2018;10:83-99.

40. Choi ES, Yoon JJ, Han BH, Da HJ, Lee HS. Ligustilide attenuates vascular inflammation and activates Nrf2/HO-1 induction and, NO synthesis in HUVECs. Phytomedicine. 2017;38:12-23.

\section{Figures}


A

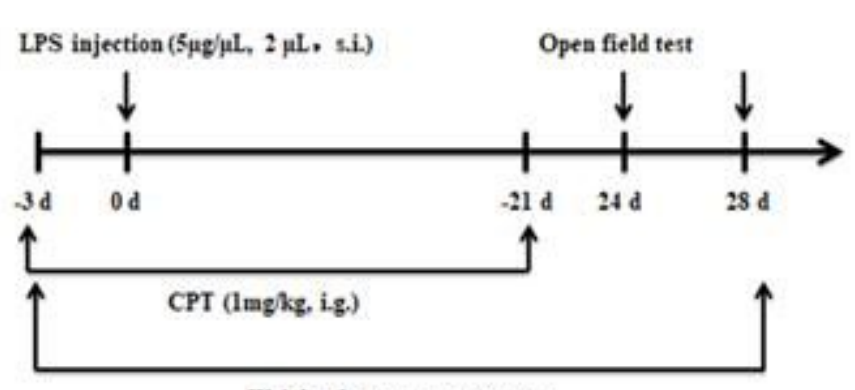

Weight change measurement

C

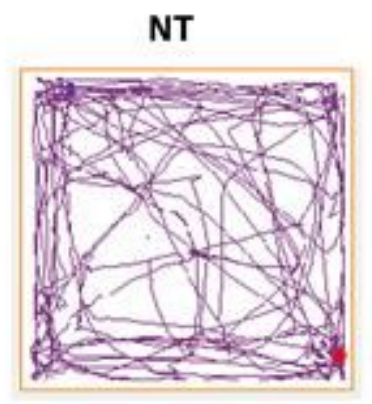

LPS

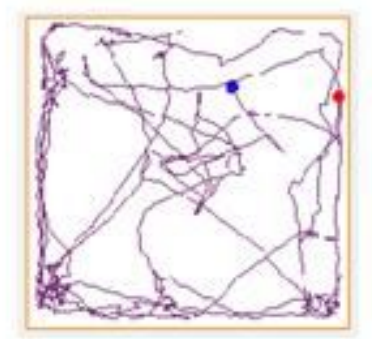

B

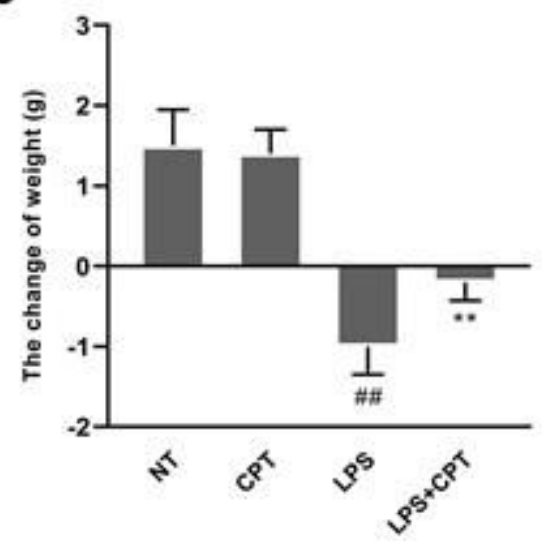

D

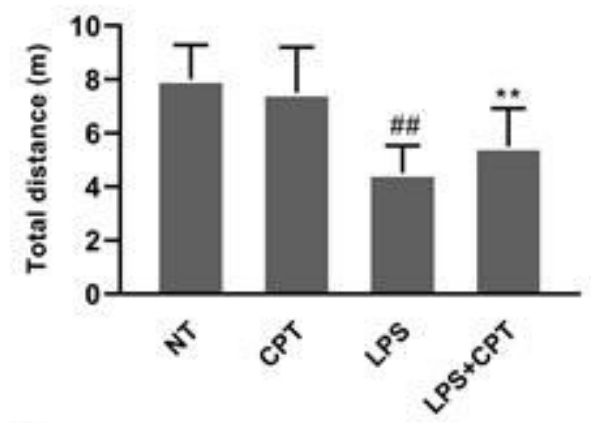

$\mathbf{E}$

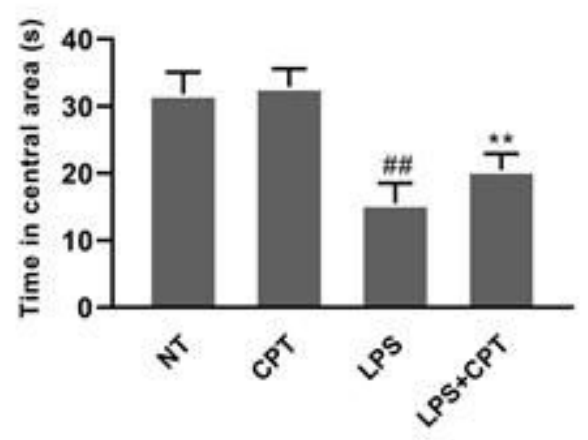

\section{Figure 1}

CPT treatment alleviates the weight loss and behavioral disorder of LPS-injected PD mouse model. (A) Experiment procedure. Mice were injected with LPS $(0.2 \mathrm{mg} / \mathrm{kg})$ or equal volume PBS into the right SNpc after anesthesia and treated every two days with CPT $(0.5 \mathrm{mg} / \mathrm{kg}) 3$ days before surgery and a total of 24 days. (B) The weight change of mice during the experiment. Before the operation and on the 28th day after the operation, the body weight of mice was measured. (C-E) The locomotor activity of mice was tested using the open field assay. Results are shown as means $\pm S D(n=5)$.\#\#p $<0.01$ vs. the notreatment (NT) group; ${ }^{* *} p<0.01$ vs. the LPS-injected group. 
A
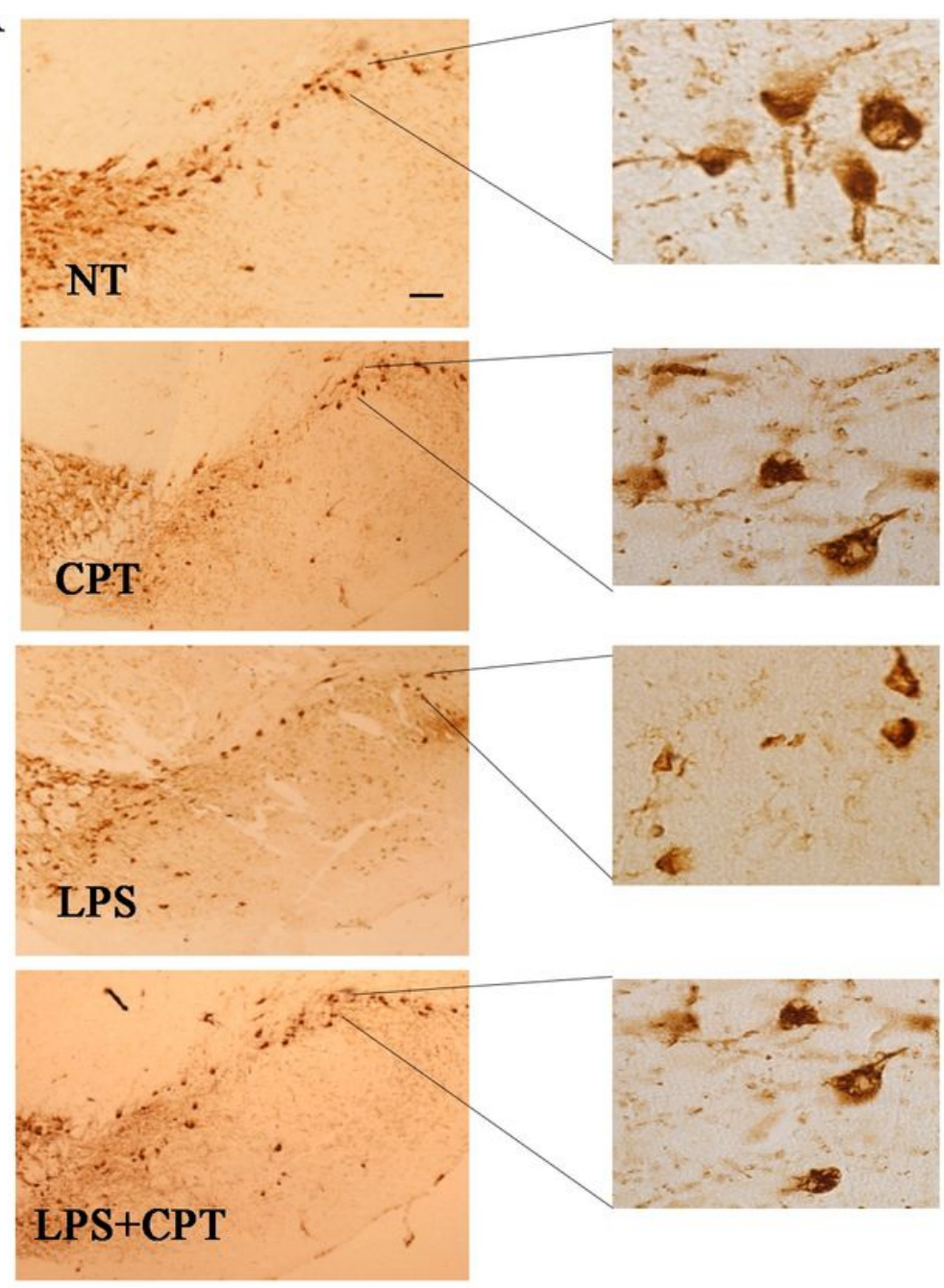

B

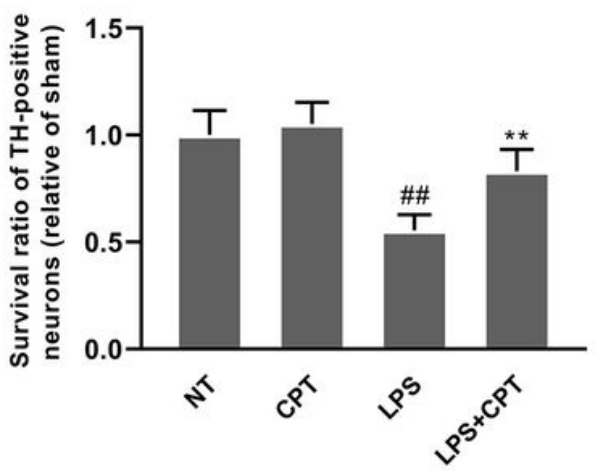

C

TH
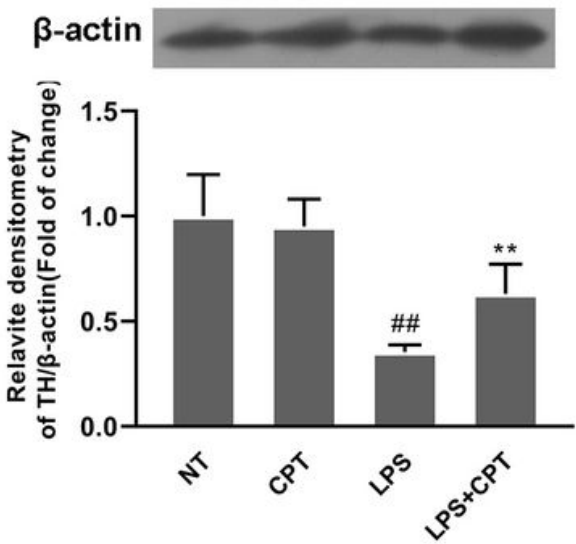

\section{Figure 2}

CPT treatment decreases dopaminergic neurons degeneration in LPS- injected PD mice. Experiment mice were anesthetized and sacrificed to obtain the midbrain on the 28th day after LPS injection. (A, B) The numbers of TH-positive cells in the SN were examined using immunohistochemistry (the scale bar represents $200 \mu \mathrm{m}$ ). (C) The protein level of TH in midbrain was examined using western blot. Results are shown as means $\pm S D(n=5)$.\#\#p $<0.01$ vs. the no-treatment (NT) group; ${ }^{* *} p<0.01$ vs. the LPS-injected group. 
A

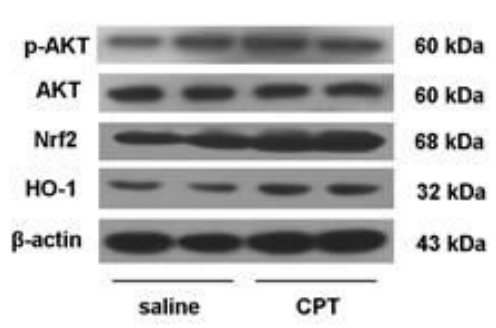

D
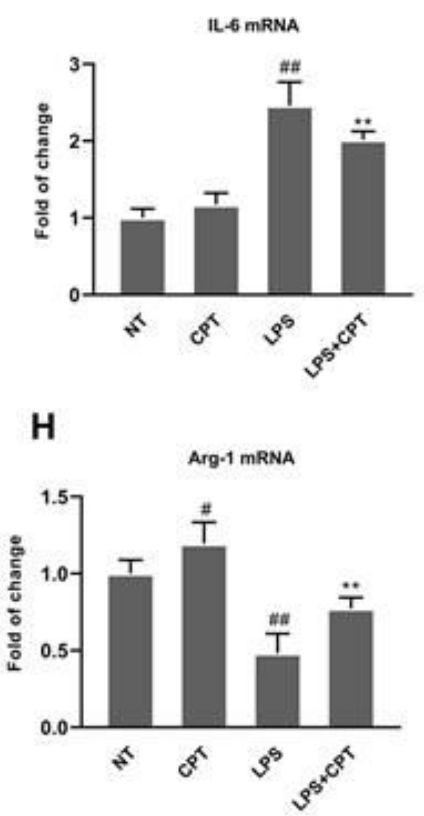

E
B

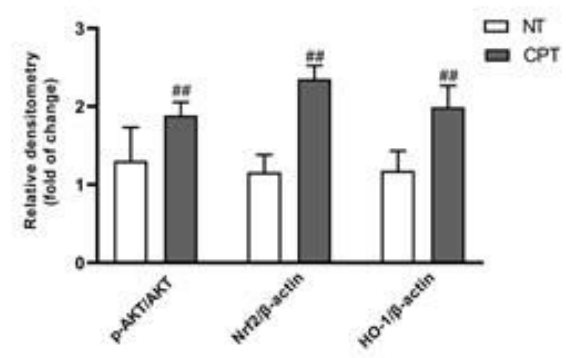

F
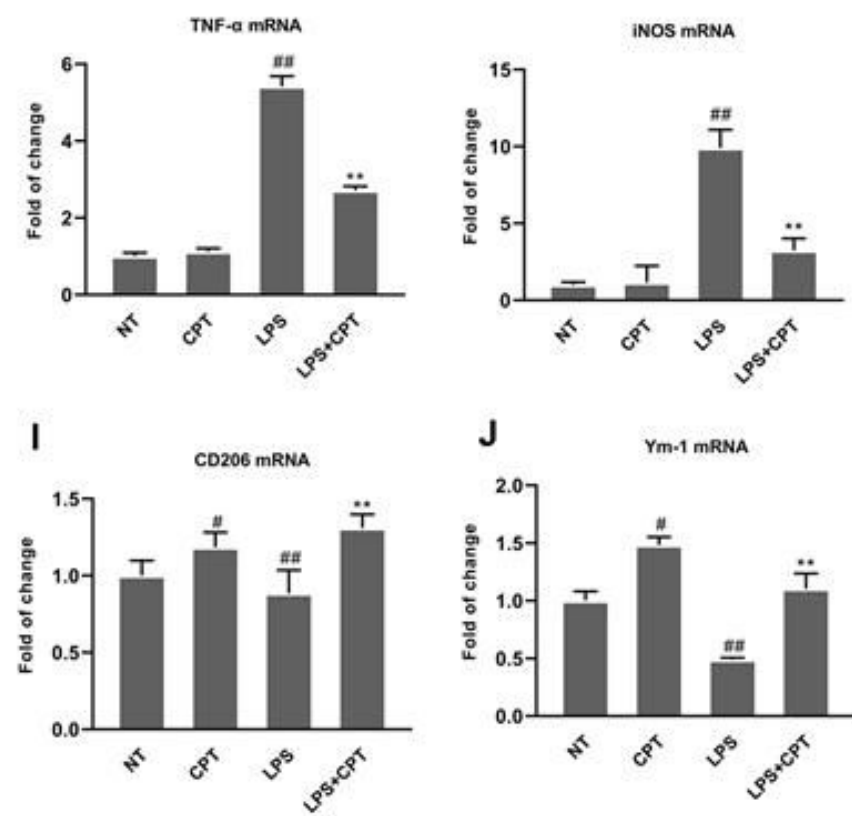

C

p-NF-KB p65

NF-KB p65

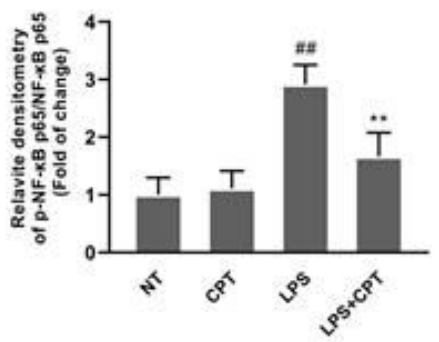

G

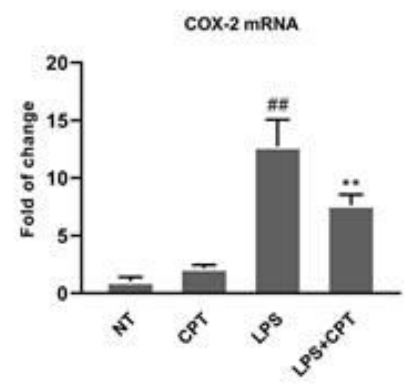

\section{Figure 3}

CPT treatment inhibits inflammatory response and regulates microglia polarization in LPS- injected PD mice. On the 28th days after modeling, the midbrain of mice was peeled off and ground. (A-C) AKT/Nrf2/HO-1-NF-KB signal axis was detected using western blot. (D-J) The mRNA levels of M1 markers (IL-6, COX-2, iNOS and TNF-a) and M2 markers (Ym-1, CD206 and Arg-1) were detected using RT-PCR. Results are shown as means $\pm S D(n=5)$.\#\#p $<0.01$ vs. the no-treatment (NT) group; ${ }^{*} p<0.01$ vs. the LPS-exposed group. 
A

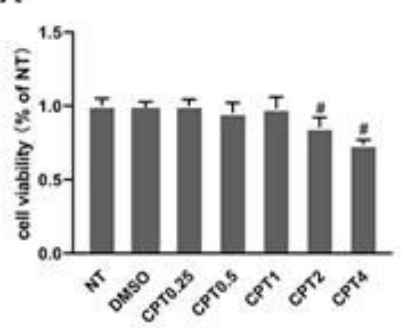

E

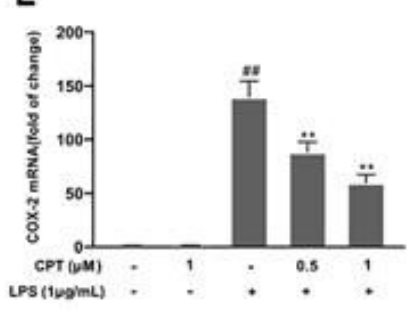

I

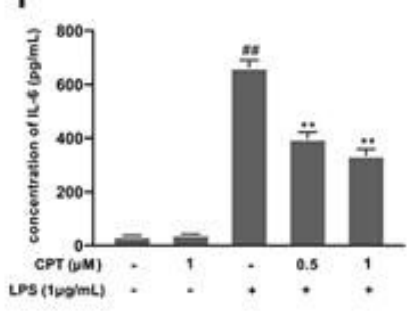

M

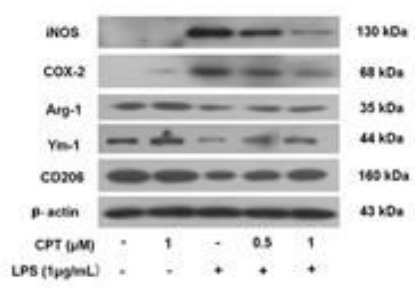

B

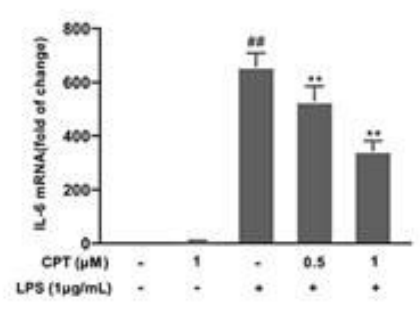

F

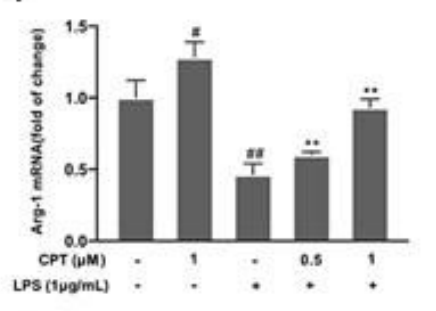

J
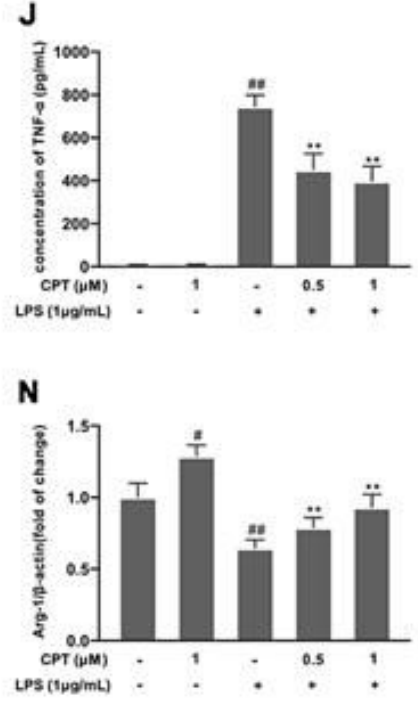

C

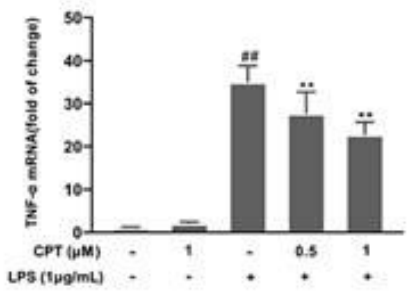

G

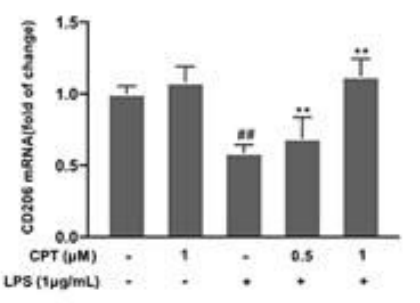

K

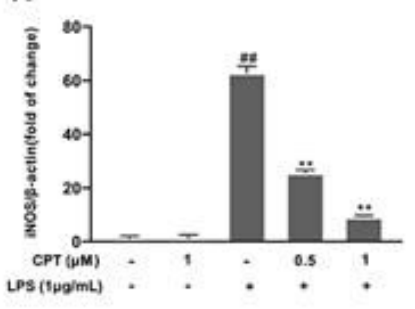

0

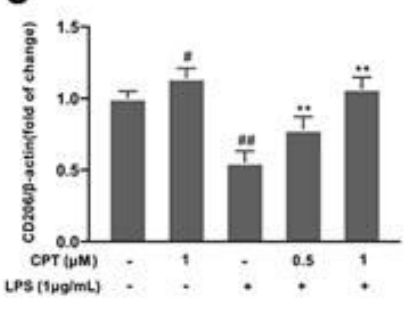

D

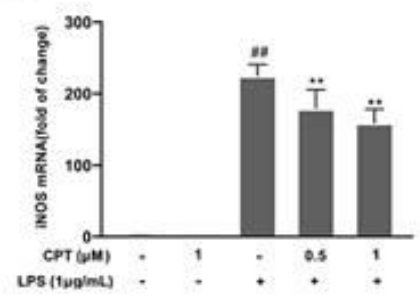

H

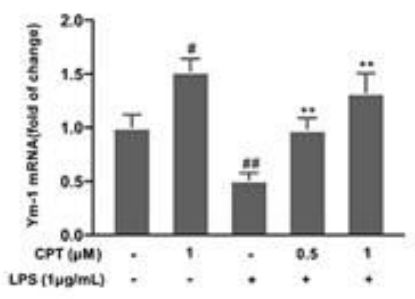

L

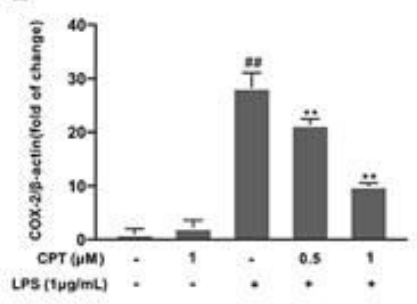

P

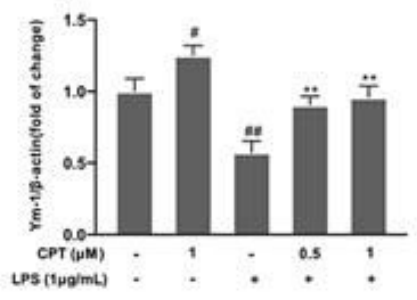

\section{Figure 4}

CPT attenuates the inflammatory response in LPS-exposed BV-2 cells. (A) The viability of BV-2 cells was measured using CCK-8 assay. The cells were pretreated with CPT $(0.5 \mu \mathrm{M}$ and $1 \mu \mathrm{M})$ for $1 \mathrm{~h}$ and then treated with LPS $(1 \mu \mathrm{g} / \mathrm{mL})$ for $12 \mathrm{~h}$ (mRNA) and $24 \mathrm{~h}$ (protein). (B-H) The mRNA levels of M1 microglia markers (IL-6, TNF-a, iNOS and COX-2) and M2 microglia markers (Ym-1, CD206 and Arg-1) were detected by RT-PCR. (I-P) The protein levels of M1 microglia markers and M2 microglia markers were measured using ELISA (IL-6 and TNF-a) and western blot (COX-2, iNOS, Arg-1, CD206 and Ym-1). Results are shown as means $\pm S D(n=5)$. \#p $<0.5$ and \#\#p $<0.01$ vs. the no-treatment (NT) group; ${ }^{* \star} p<0.01$ vs. the LPSexposed group. 
A

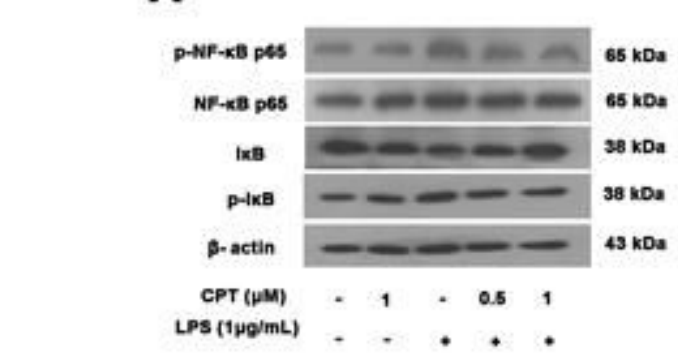

B

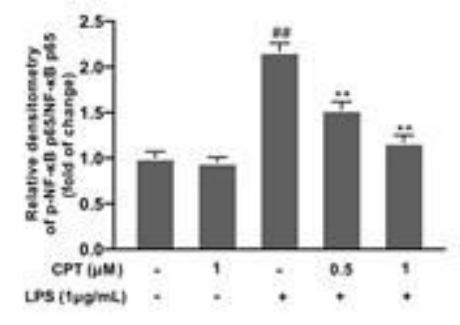

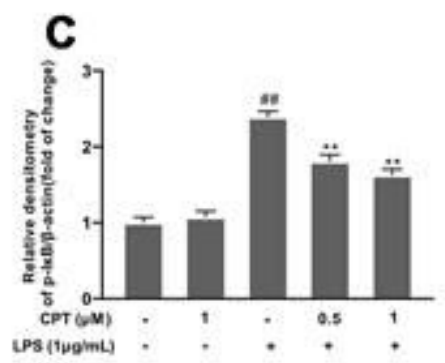
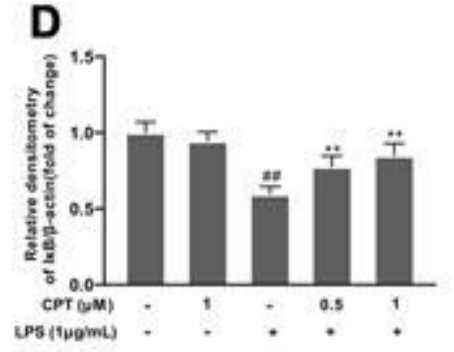
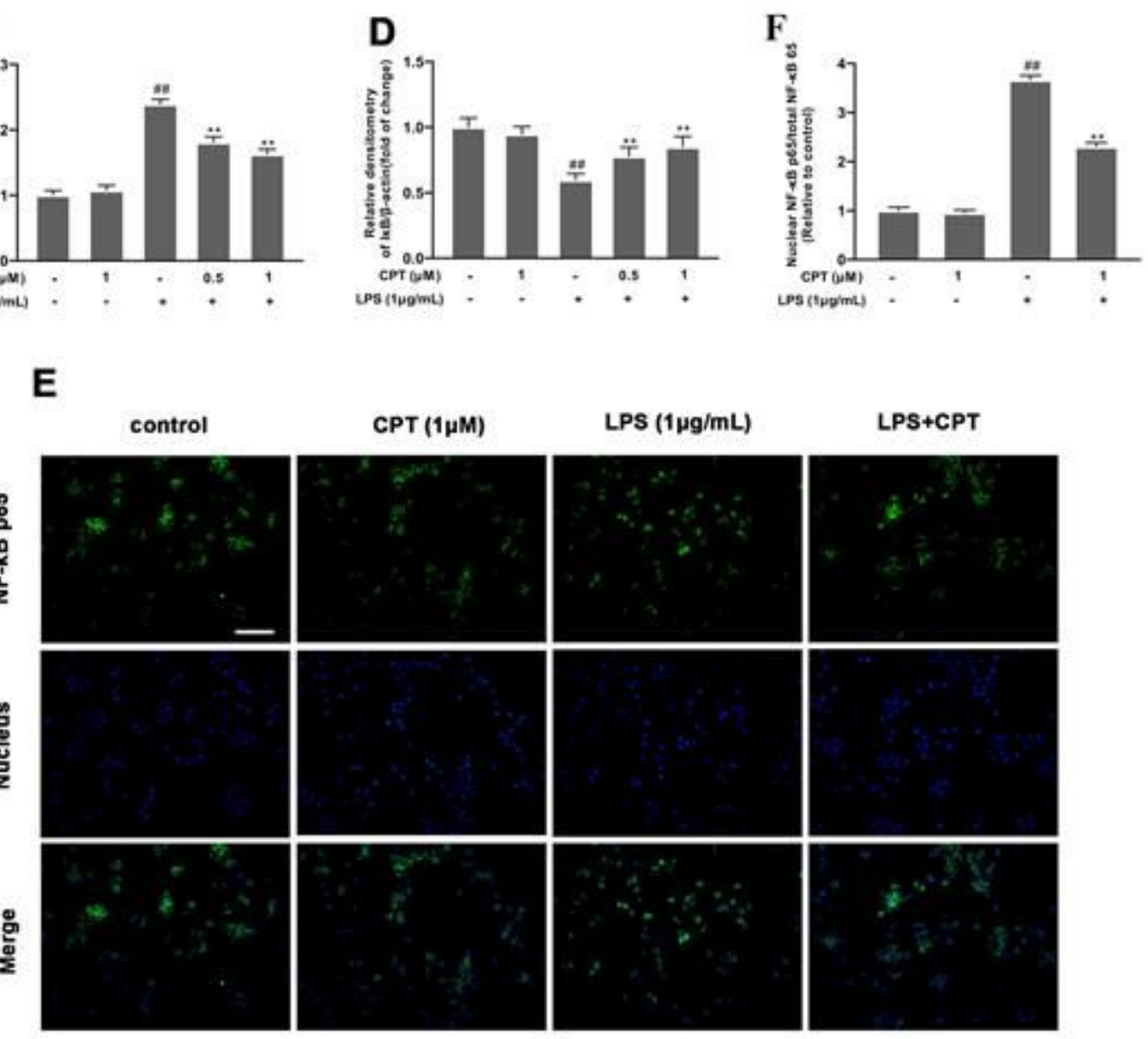

\section{Figure 5}

CPT inhibits activation of NF-KB in LPS-exposed BV-2 cells. BV-2 cells were pretreated with CPT $(0.5 \mu \mathrm{M}$ and $1 \mu \mathrm{M})$ for $1 \mathrm{~h}$ and stimulated with LPS $(1 \mu \mathrm{g} / \mathrm{mL})$ for another $1 \mathrm{~h}$. (A)The protein levels of IKB, NF-KB p65 and their phosphorylation were detected by western blot. (B) The levels of phos-NF-kB p65 were analyzed relative to NF-KB p65. (C-D) The levels of IKB and phos-IKB were analyzed relative to $\beta$-actin. (EF) The nuclear translocation level of NF-kB p65 was examined by immunofluorescence staining (the scale bar represents $200 \mu \mathrm{m})$. Results are shown as means $\pm S D(n=5)$.\#\#p $<0.01$ vs. the untreated group (NT); ${ }^{* \star} \mathrm{p}<0.01$ vs. the LPS-exposed group. 
A

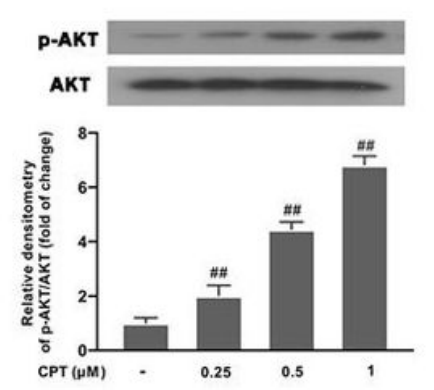

E
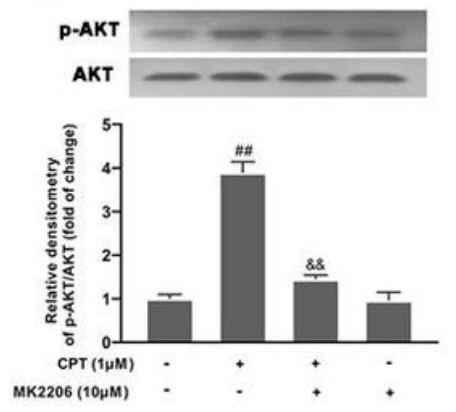

B
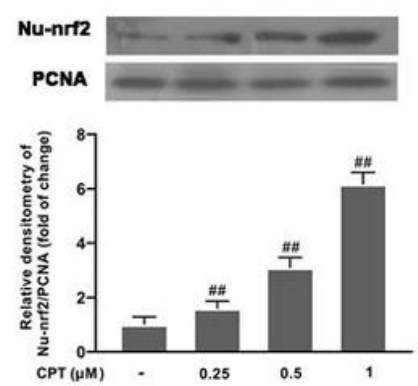

$\mathbf{F}$
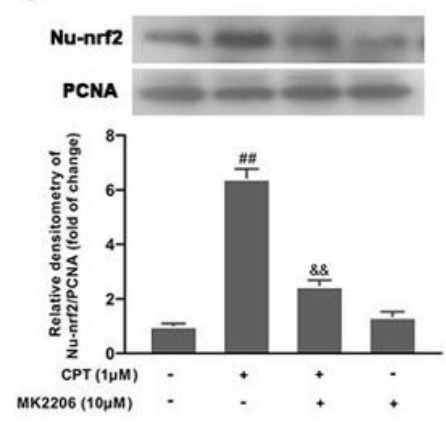

C

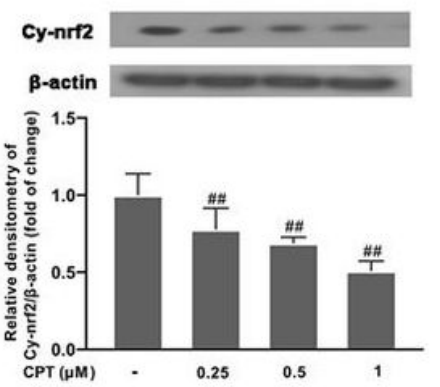

G
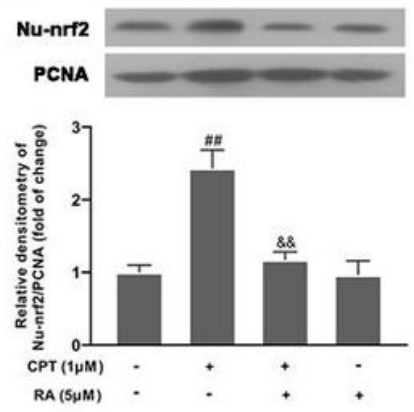

D

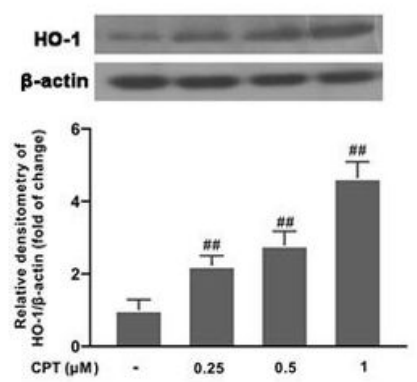

H
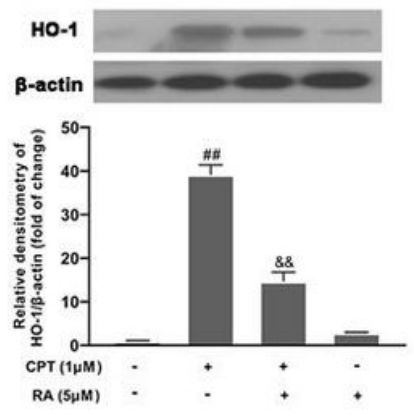

Figure 6

CPT promotes phosphorylation of AKT, activation of Nrf2 and up-regulates the expression of HO-1. (A-D) After BV-2 cells were treated with CPT $(0,0.25,0.5$ and $1 \mu \mathrm{M})$ for $3 \mathrm{~h}$, the phosphorylation of AKT, the protein levels of nuclear-nrf2, Cytoplasm-nrf2 and HO-1 were examined using western blot. (E-F) After the cells were treated with MK2206 (an AKT inhibitor, 10 $\mu \mathrm{M}$ ) for $4 \mathrm{~h}$ and CPT $(1 \mu \mathrm{M})$ for another $3 \mathrm{~h}$, the protein levels of phos-AKT and nuclear-nrf2 were determined by western blot. (G-H) After BV-2 cells were treated with RA (a nrf2 inhibitor, $5 \mu \mathrm{M}$ ) for $4 \mathrm{~h}$ and CPT $(1 \mu \mathrm{M})$ for another $3 \mathrm{~h}$, the protein levels of nuclearnrf2 and HO-1 were determined by western blot. Results are shown as means $\pm S D(n=5)$.\#\#p $<0.01$ vs. the no-treatment (NT)group; \&\&p< 0.01 vs. the CPT-treated group. 
A
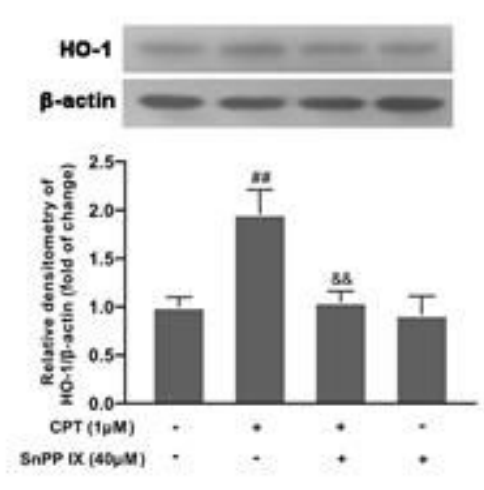

D

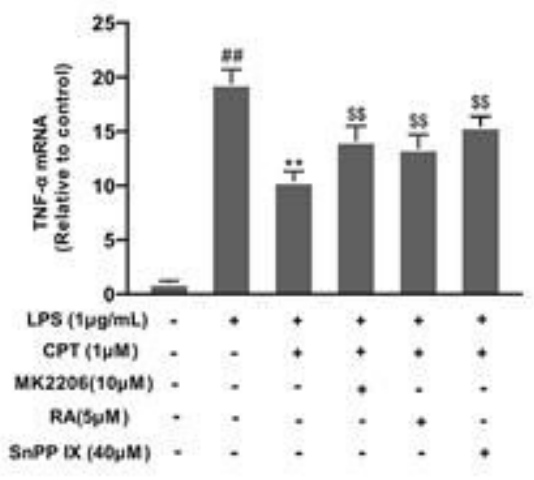

G

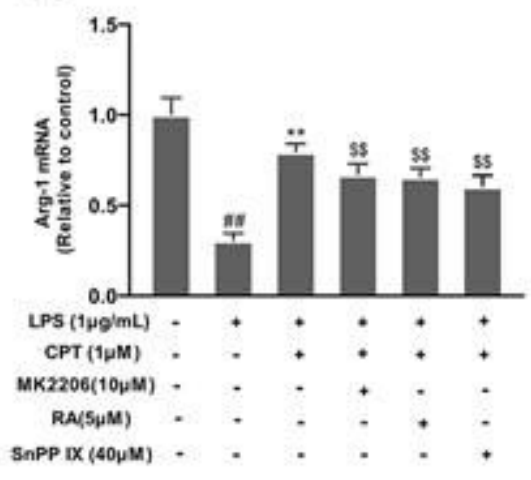

B
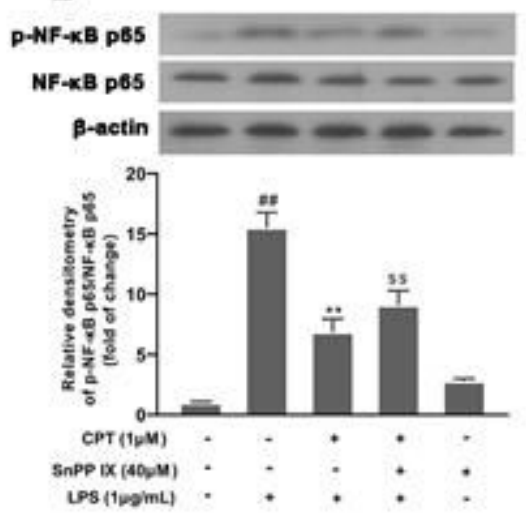

E

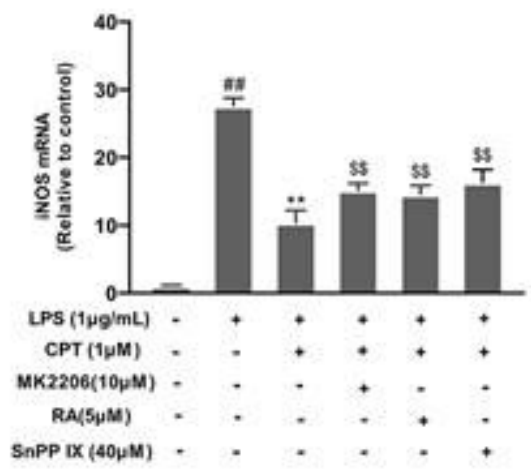

H

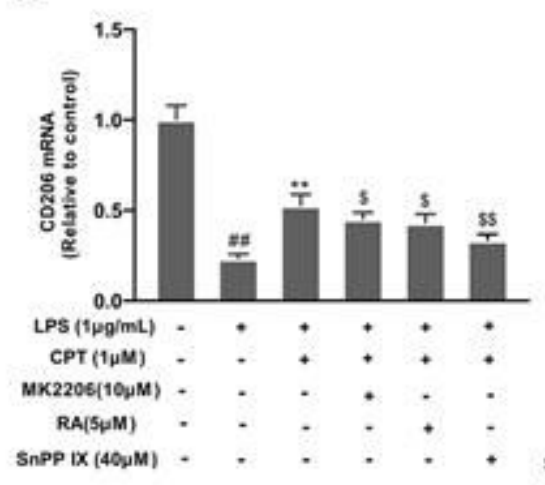

C

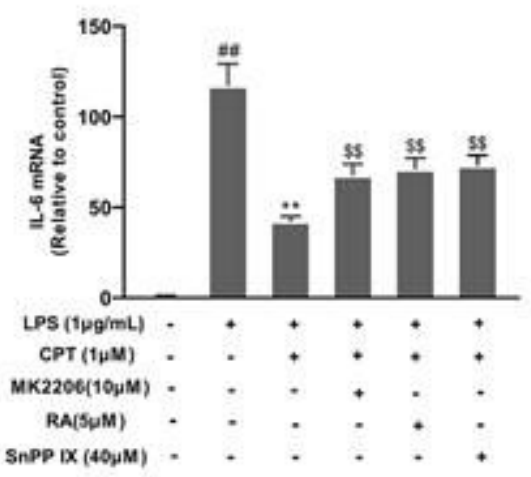

F

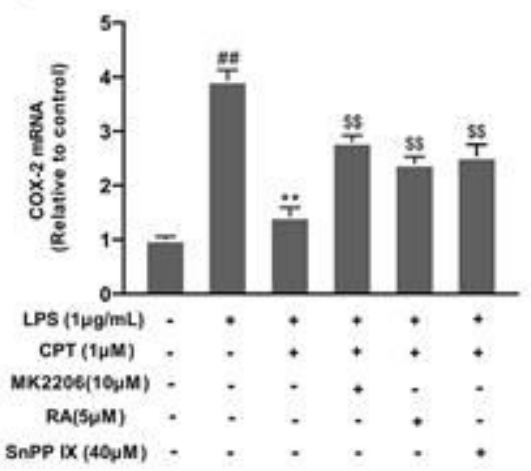

I

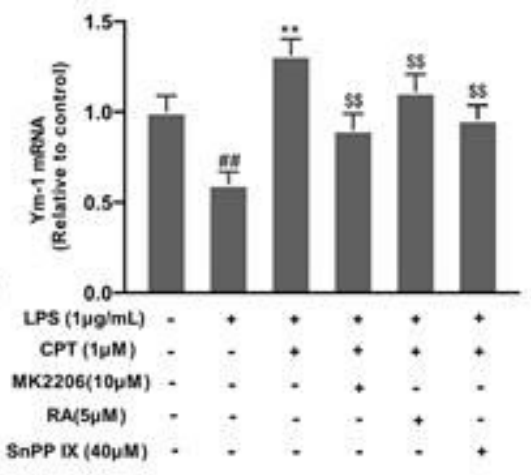

\section{Figure 7}

CPT regulates microglial polarization via AKT/ Nrf2/HO-1-NF-KB signal axis. (A) After the cells were treated with SnPP IX (a HO-1 inhibitor, $40 \mu \mathrm{M})$ for $3 \mathrm{~h}$ and CPT $(1 \mu \mathrm{M})$ for another $3 \mathrm{~h}$, the protein level of HO-1 was examined by western blot. (B) After SnPP IX treatment, the effect of CPT on NF-KB activation was detected by western blot. (C-I) The cells were treated with different inhibitors (MK2206 for 4 h, RA for $4 \mathrm{~h}$ or SnPP IX for $3 \mathrm{~h}$ ) and CPT $(1 \mu \mathrm{M})$ for $1 \mathrm{~h}$, then stimulated with LPS for $12 \mathrm{~h}$. The mRNA levels of M1 markers (IL-6, COX-2, iNOS and TNF-a) and M2 markers (CD206, Ym-1 and Arg-1) were examined using RT-PCR. Results are shown as means \pm SD $(n=5)$.\#\#p < 0.01 vs. the no-treatment (NT) group; **p< 0.01 vs. the LPS-exposed group; $\$ p<0.05$ and $\$ \$ p<0.01$ vs. the LPS+CPT-treated group. 

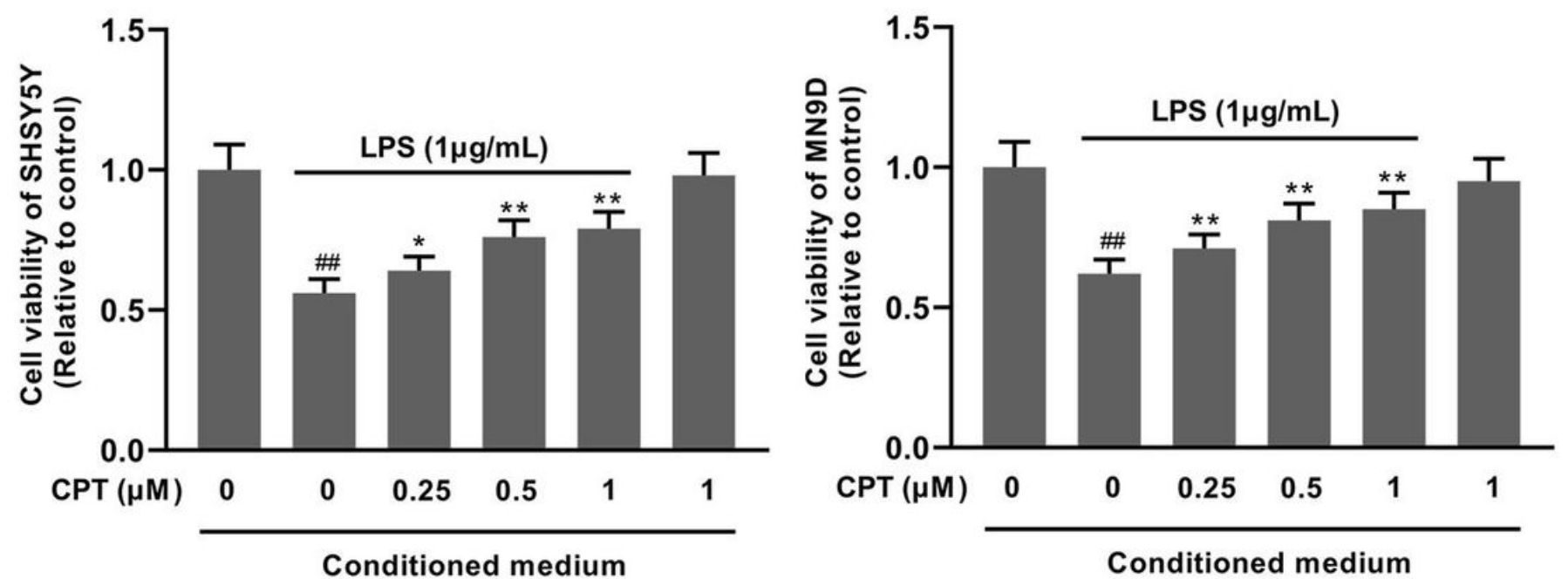

Figure 8

CPT exerts a neuroprotective effect in SHSY5Y and MN9D cells by regulating the polarization of microglia. The SHSY5Y and MN9D cells were cultured with the conditioned medium for $18 \mathrm{~h}$. The viability of the SHSY5Y (A) and MN9D (B) cells was measured using CCK-8. Results are shown as means \pm SD $(n=5) . \# \# p<0.01$ vs. the no-treatment (NT) group; ${ }^{*} p<0.01$ vs. the LPS-exposed group.

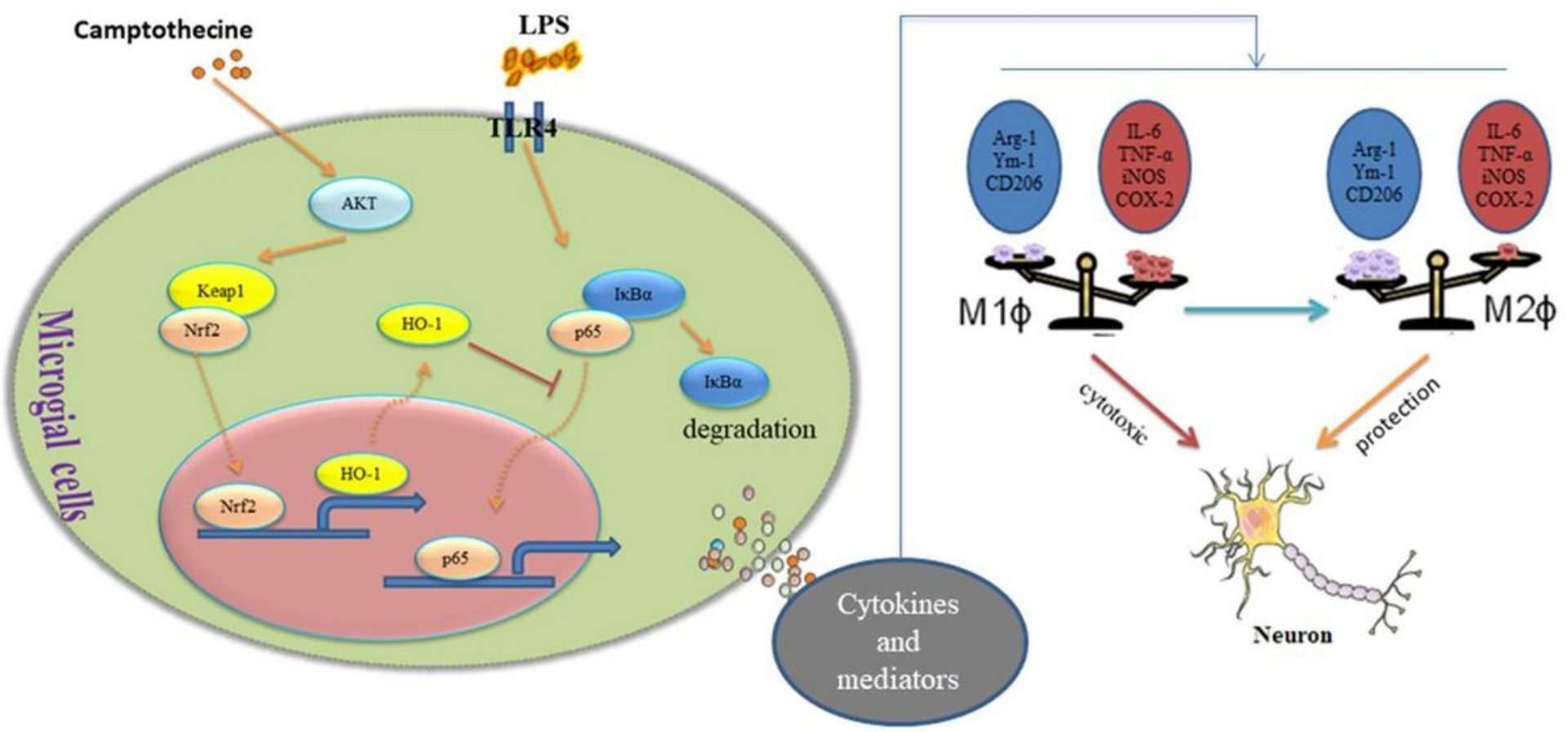

Figure 9 
Camptothecin regulates microglia polarization and exerts neuroprotective effects via the AKT/Nrf2/HO-1NF-kB signal axis. 